\title{
A new modification of Durrmeyer type mixed hybrid operators
}

\section{ARUn KaJla and TUNCER ACAR}

\section{ABSTRACT.}

In 2008 V. Miheşan constructed a general class of linear positive operators generalizing the Szász operators. In this article, a Durrmeyer variant of these operators is introduced which is a method to approximate the Lebesgue integrable functions. First, we derive some indispensable auxiliary results in the second section. We present a quantitative Voronovskaja type theorem, local approximation theorem by means of second order modulus of continuity and weighted approximation for these operators. The rate of convergence for differential functions whose derivatives are of bounded variation is also obtained.

\section{REFERENCES}

[1] Abel, U. and Ivan, M., On a generalization of an approximation operator defined by A. Lupaş, General Math., 15 (2007), No. 1, 21-34

[2] Acar, T., Asymptotic formulas for generalized Szász -Mirakyan operators, Appl. Math. Comput., 263 (2015) 233-239

[3] Acar, T. and Ulusoy, G., Approximation by modified Szász-Durrmeyer operators, Period. Math. Hung., 72 (2016), No. $1,64-75$

[4] Acar, T. Aral, A. and Raşa, I., The new forms of Voronovskaya's theorem in weighted spaces, Positivity, 20, (2016), No. $1,25-40$

[5] Acu, A. M. and Gupta, V., Direct results for certain summation-integral type Baskakov-Szász operators, Results. Math., DOI 10.1007/s00025-016-0603-2

[6] Agrawal, P. N., Gupta, V., Kumar, A. Sathish and Kajla, A., Generalized Baskakov-Szász type operators, Appl. Math. Comput., 236 (2014), 311-324

[7] Aral, A., Gupta, V. and Agarwal, R. P., Applications of $q$ Calculus in Operator Theory, Springer, (2013)

[8] Baskakov, V. A., A sequence of linear positive operators in the space of continuous functions, Dokl. Acad. Nauk. SSSR, 113 (1957), 249-251

[9] Bernstein, S. N.,Démonstration du théorème de Weierstrass fondé sur le calcul des probabilités, Commun. Soc. Math. Kharkhow (2), 13 (1912-1913), 1-2

[10] Finta, Z. and Gupta, V., Direct and inverse estimates for Phillips type operators, J. Math. Anal. Appl., 303 (2005), No. 2, 627-42.

[11] Gonska, H. Kacsó, D. and Raşa, I., On genuine Bernstein-Durrmeyer operators, Results. Math., 50 (2007), 213-225

[12] Goyal, M. Gupta, V. and Agrawal, P. N., Quantitative convergence results for a family of hybrid operators, Appl. Math. Comput., 271 (2015), 893-904

[13] Gupta, V., A note on modified Baskakov type operators, Approx. Theory Appl., 10 (1994), No. 3, 74-78

[14] Gupta, V., Direct estimates for a new general family of Durrmeyer type operators, Boll. Unione Mat. Ital., 7 (2015), No. 4, 279-288

[15] Gupta, V. and Agarwal, R. P., Convergence Estimates in Approximation Theory, Springer, (2014)

[16] Gupta, V. and Rassias, T. M., Direct estimates for certain Szász type operators, Appl. Math. Comput., 251 (2015), 469-474

[17] Gupta, V., Rassias, T. M. and Yadav, R., Approximation by Lupaş - Beta integral operators, Appl. Math. Comput., $236(2014), 19-26$

Received: 07.12.2016; In revised form: 29.05.2017; Accepted: 06.06.2017

2010 Mathematics Subject Classification. 41A25, 26A15.

Key words and phrases. Positive approximation process, rate of convergence, modulus of continuity, Steklov mean.

Corresponding author: Arun Kajla; rachitkajla47@gmail.com 
[18] Gupta, V., Srivastava, G. S. and Sahai, S., On simultaneous approximation by Szász-beta operators, Soochow J. Math., 21 (1995), No. 1, 1-11

[19] Kajla, A., Direct estimates of certain Miheşan-Durrmeyer type operators, Adv. Oper. Theory, 2 (2017), 162-178

[20] Kajla, A. and Agrawal, P. N., Szász-Durrmeyer type operators based on Charlier polynomials, Appl. Math. Comput., 268 (2015), 1001-1014

[21] Kajla, A., Acu, A. M. and Agrawal, P. N. Baskakov-Szász type operators based on inverse Pólya-Eggenberger distribution, Ann. Funct. Anal., 8 (2017), 106-123

[22] Lupaş, A., The approximation by means of some linear positive operators, in: Approximation Theory( Proceedings of the International Dortmund Meeting on Approximation Theory, Berlin, Germany, 1995), (M. W. Müller, M. Felten, D. H. Mache Eds.), Akademic Verlag, Berlin, 1995, 201-229

[23] Miheşan, V., Gamma approximating operators, Creative Math. Inf., 17 (2008), 466-472

[24] Rassias, T. M. and Gupta, V., Mathematical Analysis, Approximation Theory and Their Applications, Springer, (2016)

[25] Srivastava, H. M. and Gupta, V., A certain family of summation-integral type operators, Math. Comput. Modelling, 37 (2003), No. 12-13, 1307-1315

[26] Szász, O., Generalization of S. Bernstein's polynomials to the infinite interval, J. Res. Nat. Bur. Standards, 45 (1950), 239-245

[27] Varma, S. and Taşdelen, F., Szász type operators involving Charlier polynomials, Math. Comput. Modelling, 56 (2012), 118-122

[28] Yüksel, I. and Ispir, N., Weighted approximation by a certain family of summation integral-type operators, Comput. Math. Appl., 52 (2006), No. 10-11, 1463-1470

DePARTMENT OF MATHEMATICS

CEnTRAL University of Haryana

HARYANA-123029, INDIA

E-mail address: rachitkajla47@gmail.com

SELCUK UNIVERSITY

FACULTY OF SCIENCE

DEPARTMENT OF MATHEMATICS

SELCUKLU, KonYA, 42003, TURKEY

E-mail address: tunceracar@ymail.com 